\title{
The Girl Roster: A practical tool for strengthening girl-centered programming
}

Population Council

Follow this and additional works at: https://knowledgecommons.popcouncil.org/departments_sbsr-pgy

Part of the Demography, Population, and Ecology Commons, Family, Life Course, and Society Commons, Gender and Sexuality Commons, and the International Public Health Commons How does access to this work benefit you? Let us know!

\section{Recommended Citation}

The Girl Roster: A practical tool for strengthening girl-centered programming, fact sheet. New York: Population Council, 2019. 


\section{THE GIRL ROSTER A Practical Tool for Strengthening Girl-Centered Programming}

The Population Council developed the Girl Roster ${ }^{\mathrm{TM}}$, a practical tool designed to help practitioners understand their program areas and elicit foundational information to intentionally link girlsespecially highly marginalized adolescent girls-to the vital resources, facilities, and services to which they are entitled but often have limited or no access.

\section{The Issue}

Girls-especially the most socially and economically marginalized-are often cited as key beneficiaries of health and development initiatives. However, unless they are subject to specific, intentional recruitment efforts, they are likely to receive a disproportionately low, even negligible, share of the benefits. Good intentions aside, some "youth," "adolescent," or "girls"” programs do not apply targeted, evidence-based practices and therefore reach fewer of the most at-risk girls than they intended or could. Some programs, whether intentional or not, end up directing the majority of benefits to those who are better off and not those most in need.

\section{The Tool's Use}

The Girl Roster was developed by the Population Council in close collaboration with the Women's Refugee Commission and other members of the Girls in Emergencies (GiE) Collaborative. ${ }^{1}$ The tool is a user-friendly, efficient, and cost-effective way to collect program-relevant information about girls in a community using a mobile-phone-based questionnaire (or, where resources do not permit, paper and pencil).

The tool enables users to see a fuller view of girls' lived realities in defined program areas, comprised of easily walkable or travelable communities. Within those boundaries, the identified girls are sorted into meaningful segments by age; school-going, marital, and childbearing status; and living arrangements (living with two, one, or neither parents/guardian). The process of implementing the tool, along with the information collected itself and additional community dialogue and engagement helps local practitioners design prototype (or modify existent) programs serving different segments of girls.

\footnotetext{
${ }^{1}$ https://www.popcouncil.org/news/the-councils-girls-in-emergencies-collaborativehas-outlined-a-plan-to-meet
}
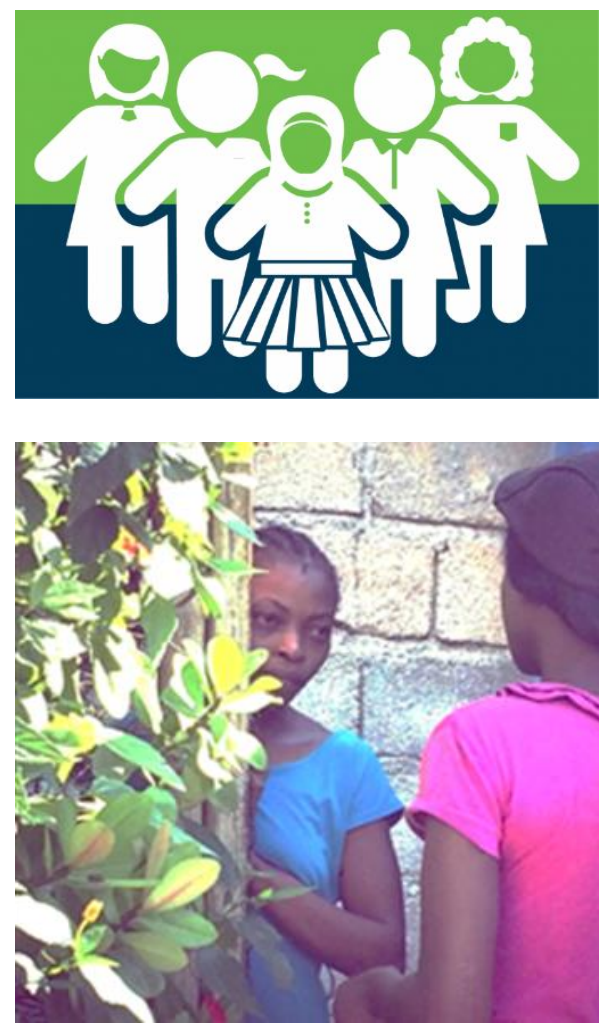

Program staff speak with the female head of household in this Haitian home to obtain consent for using the Girl Roster. Photo credit: Dana Smiles.

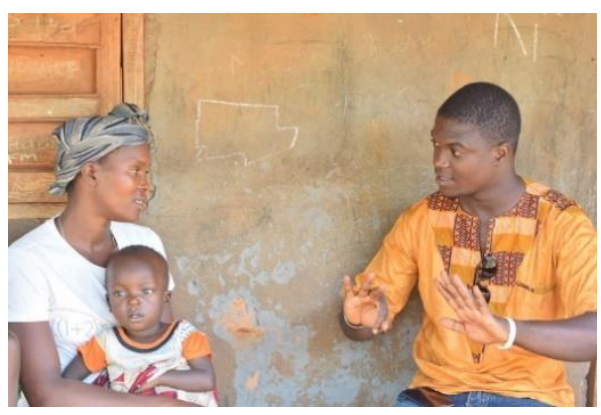

Program staff discuss the purpose of the Girl Roster with a mother in Sierra Leone. Photo credit: Sierra Leone Adolescent Girls' Network. 
The information allows practitioners to assess the degree to which populations of girls are "on-" or "off-track," according to locally affirmed commitments and laws regarding education, marriage, and childbearing, and provides insights into living arrangements and parents' and girls' access to resources.

Because the questions do not collect personal information and are not directed at the girls themselves, but rather to the female head of household, the tool helps build stronger connections between practitioner and community members, without sacrificing girls' safety or privacy while also responding to their needs. The results are generated into output tables that display information designed to help practitioners make top-level assessments of when and to what degree segments of girls are at risk.

\section{The Tool's Impact}

The Girl Roster has been utilized by approximately 100 organizations in more than 35 countries and translated into more than 15 languages (see Tables 1 and 2). It has been used by large multilateral and bilateral organizations, governments, small community-based organizations, and national networks.

Humanitarian partners, including the Women's Refugee Commission (as part of its "l'm Here" approach), have led field adaptations and translations of the Roster specifically in emergency settings, such as in Iraq, Lebanon, and South Sudan. These field experiences have continued to inform the tool's evolution.

\begin{tabular}{|l|l|}
\hline \multicolumn{2}{|l|}{ TABLE 1. Girl Roster Implementation Countries } \\
\hline Bangladesh & Lebanon \\
\hline Belize & Liberia \\
\hline Benin & Malawi \\
\hline Botswana & Mexico \\
\hline Burkina Faso & Mozambique \\
\hline Cote d'Ivoire & Namibia \\
\hline Egypt & Niger \\
\hline El Salvador & Nigeria \\
\hline Ethiopia & Rwanda \\
\hline Ghana & Sierra Leone \\
\hline Guatemala & South Africa \\
\hline Haiti & South Sudan \\
\hline Honduras & Tanzania \\
\hline India & The Gambia \\
\hline Indonesia & Turkey \\
\hline Iraq & Uganda \\
\hline Jordan & United States \\
\hline Kenya & Yemen \\
\hline Laos & Zambia \\
\hline
\end{tabular}

With interactive technical assistance from the Population Council and partners, insights from the Girl Roster's implementation improves the effectiveness of practitioners on the ground and informs scalable plans that increase program coverage. This allows most-at-risk girls to receive the protective assets they need at the right time to make a real and sustained difference.

\begin{tabular}{|l|}
\hline TABLE 2. Languages Available for Girl Roster \\
Questionnaire \\
\hline Amharic \\
\hline Arabic (various dialects) \\
\hline Bahasa \\
\hline English \\
\hline Dinka \\
\hline French \\
\hline Haitian Creole \\
\hline Hindi \\
\hline Kinyarwanda \\
\hline Kurdish \\
\hline Lao \\
\hline Portuguese \\
\hline Swahili \\
\hline Spanish \\
\hline Turkish \\
\hline
\end{tabular}

\section{The Community of Practice}

The Girl Roster was developed under the Population Council's Community of Practice.

The Council helps strengthen the capacity of different actors in designing, implementing, and evaluating effective, scalable programs that build the protective assets of adolescent girls and young women. The Council is committed to expanding evidence-based programming on the ground for girls-in partnership with community practitioners, and with the needs of specific segments of girls at the center. As such, the Council established the Adolescent Girls' Programming Community of Practice in 2013, building on 15 years of research on the conditions of girls at the highest risk for the worst outcomes.

The Community of Practice is provided with, and supported in its use of, the Council's basic model of intentional program design and complementary tools that include, but are not limited to:

- country-specific adolescent data guides;

- instructions on how to define the universe of girls in a community and assess who is reached by programs and services;

- toolkits for designing, implementing, and evaluating girls' programs including identifying the best methods of recruitment, assessments of community safety, and training and retention of mentors;

- and examples of adaptable curricula for girls' programs on topics ranging from reproductive health to financial literacy.

For more information about our Community of Practice or the Girl Roster Tool, please email us at communityofpractice@popcouncil.org 